\title{
Fear of diseases among people over 50 years of age: A survey
}

psykologisk.no/sp/2016/12/e19/

\section{We found that Alzheimer's disease and cancer were the diseases associated with the most fear among people over $\mathbf{5 0}$ years of age in our Norwegian sample, write Martin Bystad and colleagues.}

\author{
BY: Martin Bystad, Ole Grønli, Camilla Lilleeggen and Per M. Aslaksen
}

In the general population, it is reasonable to assume that serious and prevalent diseases (e.g., cancer, cardiovascular disease, and Alzheimer's disease) may evoke the most fear. For instance, fear of cancer is common (Vrinten et al., 2014). One study suggested that $59 \%$ of the respondents reported fearing cancer more than any other disease (Vrinten et al., 2014). Another study by Cantegreil-Kallen and Pin (2012) revealed that $60 \%$ of the queried patients reported fear of developing Alzheimer's disease. This fear was strongly related to age (Cantegreil-Kallen \& Pin, 2012).

One survey asked Americans which five major diseases they feared most (Harris Interactive, 2011). This survey found that $41 \%$ of the respondents reported they were most fearful of cancer, $31 \%$ that they were most fearful of Alzheimer's disease, and 8 $\%$ that they were most fearful of cardiovascular disease. This result is in accordance with another survey that queried people age 60 and older (Alzheimer's Association, 2014). It found that $35 \%$ of the respondents were most afraid of developing Alzheimer's disease, followed by cancer (25\%), stroke (15\%), diabetes (3\%), and arthritis $(2 \%)$.

Serious and prevalent diseases are frequently mentioned in the mass media and may cause people to be especially aware of them. In the United States, cancer and cardiovascular disease are the most common causes of death (Murphy, Kochanek, \& Aria, 2015). However, there is limited knowledge about fear of diseases in those aged 50 and older.

We were inspired by previous studies (Alzheimer's Association, 2014; Harris Interactive, 2011) and aimed to investigate fear of prevalent diseases among people over 50 years of age. We expected respondents to report they were most fearful of cancer, cardiovascular disease, and Alzheimer's disease and that the fear of diseases would be significantly related to age.

\section{Method}

\section{Respondents}

A total of 376 people over 50 years of age filled out the questionnaire. Of the 
respondents, $63 \%(N=239)$ were women and $37 \%(N=137)$ were men. The age range for women was 50-95 years $(M=68, S D=7.7)$ and for men was 50-87 years $(M=70, S D=7.9)$. All respondents lived in Norway.

\section{The survey}

The questionnaire included questions about age, gender, and geographical information (hometown). The respondents were instructed to report their fear of diseases on a 10point Likert scale, where "0" was "no fear" and "10" was "strong fear." The main question was: "Which of these diseases are you most afraid of getting in the future?" The following items were included in the questionnaire: "depression," "cardiovascular disease," "skin disorders," "cancer," "Alzheimer's disease," "chronic pain," "HIV," and "diabetes." These diseases were chosen based on previous studies (Alzheimer's Association, 2014; Harris Interactive, 2011) to ensure feasibility.

The questionnaire was administered by an online survey system (www.qualtrics.com). Answers were completely anonymous, and no IP addresses were registered. The survey was initiated by opening a link, which was sent electronically to six different Norwegian Senior Universities (organizations where retired individuals meet and discuss science/politics). These Senior Universities were located in Oslo, Troms, VestAgder, and Hedmark. They distributed the link to their members through their mailing lists. With such an approach it is impossible to collect data about the response rate (i.e., the number of individuals who declined participation). Approval from the Norwegian Data Protection Official for Research was not required because the survey was completely anonymous and did not involve any sensitive information.

\section{Statistical analysis}

Data were analyzed with SPSS (version 22). A linear mixed model (LMM) analysis was used. In the LMM analysis, Bonferroni's corrections were used to correct $p$-values for multiple comparisons. Age and gender were covariates in the model.

\section{Results}

As Table 1 shows that among respondents selecting "10" (strong fear), 39\% reported this score for Alzheimer's disease and $30 \%$ reported it for cancer. That was followed by chronic pain $(8.7 \%)$, depression (4\%), cardiovascular disease $(2 \%)$, diabetes $(2 \%)$, HIV $(2 \%)$, and skin disease $(0.8 \%)$. Mean scores on the fear of diseases are displayed in Table 1.

A linear mixed model analysis showed a significant main effect ( $F$ (1905.69) 2181.18, $p=0.001)$ for all diseases. Alzheimer's disease and cancer had significantly higher mean scores than did the other diseases $(p=0.001)$. The difference in mean scores between Alzheimer's disease and cancer was not significant $(p=0.99)$ nor was the impact of age on fear of disease $(F(314.18)=0.16, p=0.68)$. There was a significant 
gender difference, with females reporting significantly more fear than males $(t(323.11)=-3.46, p=0.001)$.

TABLE 1: Descriptive statistics on the survey results.

\begin{tabular}{|llllllc|}
\hline & Mean & Median & SD & Max & Min & Strong fear \\
Alzheimer's & 7.25 & 8.00 & 3.03 & 10.00 & 1.00 & $39 \%$ \\
Chronic pain & 4.84 & 5.00 & 2.96 & 10.00 & 1.00 & $8.7 \%$ \\
HIV & 1.46 & 1.00 & 1.70 & 10.00 & 1.00 & $2.0 \%$ \\
Cardiovascular & 5.35 & 5.00 & 2.65 & 10.00 & 1.00 & $2.0 \%$ \\
Depression & 3.39 & 2.00 & 2.72 & 10.00 & 1.00 & $4.0 \%$ \\
Cancer & 7.32 & 8.00 & 2.73 & 10.00 & 1.00 & $30 \%$ \\
Skin disease & 2.67 & 2.00 & 2.05 & 10.00 & 1.00 & $0.8 \%$ \\
Diabetes & 3.07 & 2.00 & 2.36 & 10.00 & 1.00 & $2.0 \%$ \\
\hline Note: Scores were based on a 10-point Likert-scale. & & & & \\
\end{tabular}

\section{Discussion}

As expected, we found fear of Alzheimer's disease and cancer to be high among the respondents. This tendency was in accord with previous results (Alzheimer's Association, 2014; Harris Interactive, 2011). Fear of these two diseases was significantly higher than that of other diseases. However, due to the high mortality associated with it, it was surprising that only $2 \%$ of the respondents reported a strong fear of cardiovascular disease.

We did not reveal any significant relationship between fear of disease and age. This finding was not expected and did not harmonize with the findings from a previous study (Cantegreil-Kallen and Pin, 2012). However, in their study, age-related fear was strongly affected by the respondents' own proximity to disease (e.g., as a caregiver), lack of information about diseases, and low level of education. A possible explanation for our findings is that aging seems to improve emotional regulation and emotional experiences (Carstensen et al., 2011). Studies have found an age-related decline in amygdala activation. This deterioration may decrease fear and intensity of unpleasant emotions (Samanez-Larkin \& Carstensen, 2012). Fear of disease and death are probably more pronounced in younger people (Erber, 2013). This could be due to emotional regulation (Carstensen et al., 2011) but also the fact that younger people 
have almost their whole life ahead of them. In addition, many younger people provide for children. This tendency could also lead to increased fear of death and diseases (Erber, 2013).

Several factors that can possibly explain why Alzheimer's disease and cancer were associated with the most fear. First, both Alzheimer's disease and cancer can have a severe emotional impact. For Alzheimer's disease, few treatment options exist, and the disease cannot be cured (Blennow, de Leon, \& Zetterberg, 2006). In addition, one hallmark of Alzheimer's disease is a progressive decline in intellectual abilities (Mayeux, 2010). In today's society, there is an intensive focus on rationality and intellectual growth (Whitehouse, Maurer, \& Ballenger, 2000); thus, the loss of intellect is a major concern with Alzheimer's disease (Alzheimer's Association, 2014). In a previous study, typical frightening aspects of Alzheimer's disease were "I will forget my loved ones," "I will become a burden to my family," and "I won't be able to take care of myself" (Alzheimer's Association, 2014).

For cancer, there are some treatment options (Waldmann, 2003). However, in $50 \%$ of the cases, cancer or its treatment leads to death (Jemal et al., 2011). Fears about personal/social implications and death are common in people who fear cancer (Vrinten et al., 2014).

Second, the mass media have focused on Alzheimer's disease and cancer in recent years. For example, Alzheimer's disease accounts for $5 \%$ of all health-related news in English newspapers (National Health Service, 2011). Similarly a large focus on cancer has taken place in the media (Clarke \& Everest, 2006). The mass media may lead people to perceive cancer as something inevitable, and frightening statistics have been emphasized (Clarke \& Everest, 2006). Fear of serious diseases may be a consequence of exposure to disease-related mass media campaigns (Marcus, Gurley, Marchi, \& Bauer, 2007). Such mass media coverage provides important health information; however, some viewers may misinterpret that information.

Third, it is reasonable to assume that Alzheimer's disease and cancer are related to a perceived lack of control. Individuals tend to fear what they cannot control. Prevention of cancer and Alzheimer's disease is found to be challenging (Selkoe, 2012; Tomasetti \& Vogelstein, 2015). This inclination may affect perceived control.

It is a paradox that few respondents indicated a high fear of cardiovascular disease because cardiovascular disease has been reported to be a major killer (Murphy, Kochanek, \& Aria, 2015). One explanation is that preventing cardiovascular disease seems to be promising (Estruch et al., 2013; Hu \& Willett, 2002). Another explanation is awareness. For instance, nearly $50 \%$ of women in America were unaware that heart disease is the major cause of death in women (Mosca et al., 2010), and only $8 \%$ of women considered cardiovascular disease to be their greatest health concern (Mosca et al., 2000). 


\section{Implications}

Our results may have implications. They indicate that reducing fear of cancer and Alzheimer's disease should be emphasized. For health care workers, it can be important to be cautious when signs of possible Alzheimer's disease or cancer exist. For instance, if a patient complains about memory loss, it is reasonable to avoid the word "Alzheimer's" before undertaking cognitive assessment. Mass media coverage of Alzheimer's disease and cancer should avoid fear-provoking headlines. The media should be cautious about headlines relying on age discriminating stereotypes (e.g., "all people above 65 years of age should undergo dementia assessment"). Fear and negativity of aging may have negative health consequences and even decrease lifespan (Officer et al., 2016). Contrarily, a positive perception of aging can increase longevity (Levy, Slade, Kunkel, \& Kasl, 2002). Levy and colleagues even found that negative perceptions of aging increased hippocampus atrophy and amyloid plaque, brain changes that are associated with Alzheimer's disease (Levy et al., 2016).

\section{Limitations}

There were limitations to our study. One shortcoming is that there may have been a selection bias in our sample (i.e., individuals with health anxiety may be most motivated to answer the survey). However, the opposite could also be possible (i.e., that people with a high level of fear avoid questions about serious diseases). In addition, our respondents participated in response to a mail calling for people over 50 years of age. This self-selected sample may be a limitation as well.

Further, we lack information about proximity with disease. Personal proximity with disease may be important for perception of fear (Cantegreil-Kallen and Pin, 2012). We also lack information about the current health status among the respondents. Some of our respondents may already suffer from the diseases in our survey (e.g., diabetes, depression, chronic pain, etc.). Such conditions can affect overall fear of diseases (van Balkom et al., 2000). However, we could not control for this possibility in our study. Another limitation is that our questionnaire was short and contained questions about eight diseases. Our survey, however, was based on previous studies (Alzheimer's Association, 2014; Harris Interactive, 2011). We made the survey short because we wanted the questionnaire to be feasible for the oldest respondents. Another limitation is that we lack information about the response rate (i.e., the number of individuals who declined participation. Our electronical survey did not provide this information.

Future studies should control for health anxiety. To investigate the risk of diseases, they should also gather information about family history, proximity with disease, current health status, and perceived risk because these factors could be of relevance. Future studies should also include younger respondents. It might be interesting to investigate possible age differences in perception of fear.

\section{Conclusion}


The present study found that Alzheimer's disease and cancer were the diseases associated with the most fear. This propensity may be attributed to the emotional impact of these diseases, mass media coverage, and perceived control. In contrast, cardiovascular disease was not associated with a high level of fear. Age had no significant impact on the fear of diseases. Our results demonstrate the need for further investigation. Future studies should control for health anxiety, perceived risk, and family history.

\section{References}

Alzheimer's Association (2014). Alzheimer's disease facts and figures. Alzheimer's \& Dementia, 10, e47-e92. doi:10.1016/j.jalz.2014.02.001

Blennow, K., de Leon, M. J., \& Zetterberg, H. (2006). Alzheimer's disease. The Lancet, 368, 387-403. doi:10.1016/S0140-6736(06)69113-7

Cantegreil-Kallen, I., \& Pin, S. (2012). Fear of Alzheimer's disease in the French population: Impact of age and proximity to the disease. International Psychogeriatrics, 24, 108-116. doi:10.1017/S1041610211001529

Carstensen, L., Turan, B., Scheibe, S., Ram, N., Ersner-Hershfield, H., \& SamanezLarkin, G. R. (2011). Emotional experience improves with age: Evidence based on over 10 years of experience sampling. Psychological Aging, 26, 21-33. doi:10.1037/a0021285

Clarke, J.N., \& Everest, M.M. (2006). Cancer in the mass print media: Fear, uncertainty, and the medical model. Social Science \& Medicine, 62, 2591-2600. doi:10.1016/j.socscimed.2005.11.021

Erber, J. T. (2013). Aging and older adulthood. New Jersey: Wiley-Blackwell.

Estruch, R., Rose, E., Salas-Salvadó, J., Covas, M.-I., Corella, D., Arós, F., GómezGracia, E. et al. (2013). Primary prevention of cardiovascular disease with a Mediterranean diet. New England Journal of Medicine, 368, 1279-1290. doi:10.1056/NEJMoa1200303

Harris Interactive (2011). What America thinks: MetLife Foundation Alzheimer's survey. https://www.metlife.com/assets/cao/foundation/alzheimers-2011.pdf

Hu, F. B., \& Willett, W. C. (2002). Optimal diets for prevention of coronary heart disease. JAMA, 288, 2569-2578. doi:10.1001/jama.288.20.2569

Jemal, A., Bray, F., Center, M. A., Ferlay, J., Ward, E., \& Forman, D. (2011). Global cancer statistics. CA: A cancer journal for clinicians, 61, 69-90. 
Levy, B. R., Ferucci, L., Zonderman, A. B., Slade, M. D., Tronocoso, J., \& Resnick, S. M. (2016). A culture-brain link: Negative age stereotypes predict Alzheimer's disease biomarkers. Psychology and Aging, 31, 82-88. doi:10.1037/pag0000062

Levy, B. R., Slade, M., Kunkel, S. R., \& Kasl, S. V. (2002). Longevity increased by positive self-perceptions of aging. Journal of Personality and Social Psychology, 83, 261-270. doi:10.1037/0022-3514.83.2.261

Marcus, D. K., Gurley, J. R., Marchi, M. M., \& Bauer, C. (2007). Cognitive and perceptual variables in hypochondriasis and health anxiety: A systematic review. Clinical Psychology Review, 27, 127-139. doi:10.1016/j.cpr.2006.09.003

Mayeux, R. (2010). Early Alzheimer's Disease. New England Journal of Medicine, 362, 2194-2201. doi:10.1056/NEJMcp0910236

Mosca, L., Jones, W. K., King, K. B., Ouyang, P., Redberg, R. F., \& Hill, M. N. (2000). Awareness, perception, and knowledge of heart disease risk and prevention among women in the United States. Archives of Family Medicine, 9, 506.

doi:10.1001/archfami.9.6.506

Mosca, L., Mochari-Greenberger, H., Dolor, R. J., Newby, L. K., \& Robb, K. J. (2010). Twelve-year follow-up of American women's awareness of cardiovascular disease risk and barriers to heart health. Circulation Cardiovascular Quality Outcomes, 3, 120-127. doi:10.1161/CIRCOUTCOMES.109.915538

Murphy, S. L., Kochanek, K. D. J., \& Aria, E. (2015). Mortality in the United States in 2014. National Center for Health Statistics, 229, 1-8.

http://www.cdc.gov/nchs/products/databriefs/db229.htm

National Health Service (2011). Alzheimer's in the news: Fear and fascination. http://www.repod.org.uk/downloads/inthenews.pdf

Officer, A., Schneiders, M. L., Wu, D., Nash, P., \& Thiagarajan, J. A. (2016). Valuing older people: Time for a global campaign to combat ageism. Bulletin of the World Health Organization, 94, 710-710A. doi:10.2471/BLT.16.184960

Samanez-Larkin, G. R., \& Carstensen, L. L. (2012). Socioemotional functioning and the aging brain. In J. Decety \& J. T. Cacioppo (Eds.), The handbook of social neuroscience. New York, NY: Oxford University Press.

Selkoe, D. J. (2012). Preventing Alzheimer's disease. Science, 337, 1488-1492. doi:10.1126/science.1228541

Tomasetti, C., \& Vogelstein, B. (2015). Variation in cancer risk among tissues can be explained by the number of stem cell divisions. Science, $347,78-81$.

doi:10.1126/science.1260825

van Balkom, A. J., Beekman, A. T., de Beurs, E., Deeg, D. J., van Dyck, R., \& van 
Tilburg, W. (2000). Comorbidity of the anxiety disorders in a community-based older population in The Netherlands. Acta Psychiatrica Scandinavica, 101, 37-45.

doi:10.1034/j.1600-0447.2000.101001037.x

Vrinten, C., McGregor, L.M., Heinrich, M., von Wagner, C., Waller, J., Wardle, J., \&

Black, B. B. (2014). What do people fear about cancer? A systematic review and metasynthesis. The Lancet, 384, 12. doi:10.1016/S0140-6736(14)62138-3

Vrinten, C., van Jaarsveld, C. H., Waller, J., von Wagner, C., \& Wardle, J. (2014). The structure and demographic correlates of cancer fear. BMC Cancer, 14, 597. doi:10.1186/1471-2407-14-597

Waldmann, T. A. (2003). Immunotherapy: Past, present, and future. Nature Medicine, 9, 269-277. doi:10.1186/1471-2407-14-597

Whitehouse, P.J., Maurer, K., \& Ballenger, J. (2000). Concepts of Alzheimer's Disease: Biological, Clinical, and Cultural Perspectives. Baltimore: John Hopkins Press.

Citation

Bystad, M., Grønli, O., Lilleeggen, C., \& Aslaksen, P. M. (2016). Fear of diseases among people over 50 years of age: A survey. Scandinavian Psychologist, 3, e19. https://doi.org/10.15714/scandpsychol.3.e19

Abstract

\section{Fear of diseases among people over 50 years of age: A survey}

The aim of this study was to investigate the association between well-known diseases and fear of them in individuals over 50 years of age. Information on the fear of diseases can be relevant for both public health information purposes and clinical setting diagnostics. However, very few studies have investigated the fear of diseases in individuals over the age of 50 . We used an electronic survey method and asked individuals older than 50 to report their fear of eight different diseases. Fear of diseases was the outcome measure. A 10-point Likert scale questionnaire was used to assess the fear of contracting different diseases, including cancer, Alzheimer's disease, cardiovascular disease, HIV, depression, diabetes, skin disorders (eczema and psoriasis), and chronic pain. There were 376 respondents. Cancer and Alzheimer's disease were associated with the most fear. Fear of these two diseases was significantly higher than for other diseases $(p=0.01)$. Age had no significant impact on the fear of diseases $(p=0.68)$. Of the 376 respondents, $39 \%$ reported a strong fear (10 points) of Alzheimer's disease, whereas 30\% reported a strong fear of cancer. Only $2 \%$ reported a strong fear of cardiovascular disease. This study suggests that cancer and Alzheimer's disease evoke the most fear. 
Keywords: aging, Alzheimer's disease, cancer, fear of diseases, health concerns.

Author affiliations: Martin Bystad - Department of Psychology, University of Troms $\varnothing$, Troms $\varnothing$, Norway \& Division of Geriatric Psychiatry, University Hospital of North Norway, Tromsø, Norway; Ole Grønli - Division of Geriatric Psychiatry, University Hospital of North Norway, Tromsø, Norway; Camilla Lilleeggen - Department of Psychology, University of Troms $\varnothing$, Troms $\varnothing$, Norway; Per M. Alaksen - Department of Psychology, University of Tromsø, Tromsø, Norway \& Division of Child and Adolescent Health, University Hospital of North Norway, Troms $\varnothing$, Norway.

Contact information: Martin Bystad, Department of Psychology, University of Troms $\varnothing$ - The Arctic University of Norway, Pb. 6050 Langnes, N-9037 Tromsø, Norway.

Email: martin.k.bystad@uit.no.

Received: August 1, 2016. Accepted: November 28, 2016. Published: December 11, 2016.

Language: English.

Competing interests: The authors report no conflict of interest. The authors alone are responsible for the contents and writing of this paper.

This is a peer-reviewed paper. 